\title{
A Longitudinal Examination of the Relationship between Physical Aggression and Violent Victimization among Urban Minority Chicago Youth and Young Adults
}

\author{
Wesley G. Jennings", ${ }^{*}$ and Kelli A. Komro ${ }^{2}$ \\ ${ }^{1}$ University of South Florida, College of Behavioral and Community Sciences, Department of Criminology, 4202 E. \\ Fowler Ave., SOC 326, Tampa, FL 33620, USA \\ ${ }^{2}$ University of Florida, College of Medicine, Department of Health Outcomes and Policy, and Institute for Child Health \\ Policy, 1329 SW $16^{\text {th }}$ St. Room 5130, PO Box 100177, Gainesville, FL 32610-0177, USA
}

\begin{abstract}
Empirical evidence has been accumulating suggesting that victims and offenders share common risk factors and are often one and the same. Guided by this extant literature, this study provides a longitudinal examination of the relationship between physical aggression and violent victimization among a large sample of 2,671 urban minority youth and young adults from Chicago. The results from a series of bivariate probit regression models, which allow the equations for physical aggression and violent victimization to be estimated simultaneously, reveal strong evidence of a victimoffender overlap. Additional results suggest that this victim-offender overlap cannot be merely explained away by a commonality of risk factors and demographics alone. Study limitations and policy implications are also discussed.
\end{abstract}

Keywords: Physical aggression, victimization, victim-offender overlap.

\section{INTRODUCTION}

Routine activities/lifestyles perspective is perhaps the most prominent criminological theory of victimization. Studied at length and created by Cohen and Felson (1979) and Hindelang, Gottfredson, and Garofalo (1978), this perspective views victimization as a by-product of ordinary activities such as alcohol consumption that bring easily targeted individuals into contact with potential offenders [13]. Drawing further on the work of the earlier theorists, Jensen and Brownfield (1986) went a step further by viewing a person's criminal activity as a lifestyle that also carries with it a high risk of victimization [4]. This perspective emphasizes that criminal activities are often done in group settings whereby individuals situate themselves in a social context of greater exposure to potential offenders [5]. A growing body of evidence has supported this hypothesis demonstrating that delinquent peers tend to be less effective protectors from victimization experiences [5-7].

While routine activity/lifestyles theory can explain why offenders become victims it does not necessarily explain how victims become offenders. Therefore, other theories have expanded routine activity/lifestyles theory to provide this perspective [3]. Causal perspectives associated with this theoretical framework suggest that unstructured activity away from authority figures increases opportunities to engage in criminal activities. Specifically, youth who are engaging in risky activities (and hanging out with peers

*Address correspondence to this author at the College of Behavioral and Community Sciences, Department of Criminology, 4202 E. Fowler Ave., SOC 326, Tampa, FL 33620, USA; Tel: 813-974-8024; Fax: 813-974-2803; E-mail: jenningswgj@usf.edu similarly involved in risky activities) are more likely to become both offenders and victims of crime [8].

Subcultural (Singer, 1981) and social interactionist theories (Felson, 1992) have also been offered as theoretical explanations for offending and victimization $[9,10]$. For example, Singer demonstrated that within subcultures of violence, individuals who have attacked and victimized others risk retaliation from former victims [3]. Additional research examining violence among women in Philadelphia [11] and disorganized communities in both Philadelphia [12] and St. Louis [13] have since corroborated Singer's earlier findings. Furthermore, it has been argued that, in many communities, social norms require victims to retaliate in order to maintain respect, so as not to lose face, e.g., an informal code-of-the-street exists that governs behavior and favors 'might makes right' [3, 14]. Similarly, Felson (1992) used social interactionist theory to examine and elaborate on the role of conflict, retaliation, and aggression and victimization and violence [10]. Felson suggested that being distressed due to victimization interferes with how people interact, which in turn leads to conflict and ultimately causes them to attack and retaliate [3].

Acknowledging these theoretical perspectives and the prior empirical research suggesting an overlap among victims and offenders [3, 15-22], we provide a longitudinal examination of how these outcomes may be intrinsically linked among a large sample of urban minority youth and young adults from Chicago. Specifically, we hypothesize that: 1) physical aggression and violent victimization are shared experiences among urban minority youth and young adults; and 2) the association between perpetrating physical aggression and experiencing violent victimization among urban minority youth and young adults cannot be merely 
explained away by either demographic variables or a shared commonality of risk factors.

\section{RESEARCH DESIGN}

Data were derived from Project Northland Chicago (PNC), a group-based randomized trial that tested the efficacy of an alcohol preventive program for multi-ethnic urban youth $[23,24]$. A cohort of youth enrolled in 61 public schools in Chicago participated in the study (29 schools assigned to the intervention, 32 to the comparison group) and completed self-report questionnaires when in $6^{\text {th }}, 7^{\text {th }}, 8^{\text {th }}$ and $12^{\text {th }}$ grade. Four school-based surveys were conducted in $6^{\text {th }}$ $8^{\text {th }}$ grade (between 2002 and 2005) and the most recent multimodal survey was conducted in $2008-2009$ (12 $2^{\text {th }}$ grade). The overall response rate for study from $6^{\text {th }}-12^{\text {th }}$ grade was $53 \%$. Further details on the research design, sample characteristics, and measures can be found elsewhere [24, 25]. Parental consent and student assent procedures were approved by the University of Minnesota and University of Florida Institutional Review Boards and the Chicago Public Schools' Law Department, with secondary data analysis approved by the University of South Florida's IRB. A Certificate of Confidentiality was obtained from the U.S. Department of Health and Human Services to further protect the confidentiality of the student responses.

\section{SAMPLE}

The current study includes 2,671 African American and Hispanic youth and young adults who completed a follow-up survey at the end of 8 th grade. Approximately 54\% of this sample of African American and Hispanic youth $(n=1,440)$ completed the $12^{\text {th }}$ grade follow-up survey and provided $12^{\text {th }}$ grade outcome data for physical aggression and violent victimization. Males comprised $48.5 \%$ of the sample and the average age of the youth at the end of $8^{\text {th }}$ grade was 14.29 years old $(\mathrm{SD}=0.50)$. The majority of the youth and young adults were African American (56.2\%), from low socioeconomic status households $(79.5 \%)$, and were born in the U.S. (86.7\%). Less than half of the youth and young adults resided in a natural two parent household $(43.5 \%)$. Table 1 provides additional descriptive statistics for the participants in this study, and Fig. (1) provides an illustration of the prevalence of physical aggression, violent victimization, and the overlap of physical aggression and violent victimization.

\section{MEASURES}

\section{Dependent Variables}

Physical aggression. A physical aggression index was created based on the following three items: During the last month, how many times have you: (1) pushed, shoved, pulled someone's hair, or grabbed someone?; (2) kicked, hit, or beat up another person?; (3) taken part in a fight, where a group of your friends were against another group? Responses to each of these three items included: "Never," "1-3 times," and " 4 or more times". The continuous measure was retained as the measure of prior physical aggression to adjust for baseline effects $\left(8^{\text {th }}\right.$ grade), whereas this index was dichotomized for analytic purposes for use as the dependent variable based on $12^{\text {th }}$ grade responses.

Violent Victimization. Victimization was assessed by using the following two items: "During the last 12 months, has someone injured you on purpose?" and "During the last 12 months, has someone threatened to injure you, but not actually injured you?" Responses included: "Not at all, once, twice, 3 or 4 times, 5 or more times". Similar to the physical aggression measure, this particular index was dichotomized

Table 1. Descriptive Statistics among 8th Grade Sample

\begin{tabular}{|c|c|c|c|c|}
\hline Variables & $\mathbf{M} / \%$ & SD & Minimum & Maximum \\
\hline \multicolumn{5}{|l|}{ Risk Factors } \\
\hline Alcohol Use & $41.1 \%$ & -- & 0.00 & 1.00 \\
\hline Peer Alcohol Use (number of friends drink) & 1.35 & 1.24 & 0.00 & 4.00 \\
\hline Lack of Supervision (hrs unsupervised/day) & 2.14 & 1.32 & 0.00 & 4.00 \\
\hline Sadness/Depression ${ }^{1}$ & 0.97 & 0.79 & 0.00 & 2.00 \\
\hline \multicolumn{5}{|l|}{$\underline{\text { Demographics }}$} \\
\hline Male & $48.5 \%$ & -- & 0.00 & 1.00 \\
\hline Age & 14.29 & 0.50 & 12.67 & 16.45 \\
\hline Natural Parent Household & $43.5 \%$ & -- & 0.00 & 1.00 \\
\hline African American & $56.2 \%$ & -- & 0.00 & 1.00 \\
\hline U.S. Born & $86.7 \%$ & -- & 0.00 & 1.00 \\
\hline Low Socioeconomic Status ${ }^{2}$ & $79.5 \%$ & -- & 0.00 & 1.00 \\
\hline Prior Physical Aggression ${ }^{3}$ & 2.45 & 1.86 & 0.00 & 6.00 \\
\hline \multicolumn{5}{|l|}{ Outcomes } \\
\hline Perpetrator of Physical Aggression $\left(12^{\text {th }} \text { grade }\right)^{4}$ & $44.5 \%$ & -- & 0.00 & 1.00 \\
\hline Victim of Violence $\left(12^{\text {th }} \text { grade }\right)^{5}$ & $19.5 \%$ & -- & 0.00 & 1.00 \\
\hline
\end{tabular}

Note: 1 : $0=$ never, $1=1-3$ times, $2=4+$ in past month; 2 : receive free/reduced price lunch; 3 : three items added with response options $0=$ never, $1=1-3$ times, $2=4+$ in past month physical aggression; 4: 1 or more times in past month for any physical aggression; and 5: 1 or more times in past month for any violent victimization. 
for analytic purposes for use as an outcome variable based on $12^{\text {th }}$ grade responses.

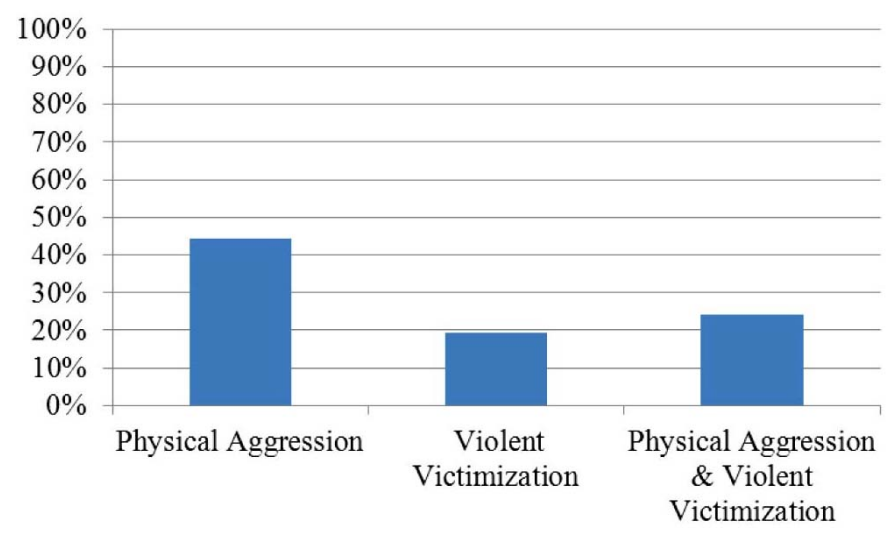

Fig. (1). Prevalence of Physical Aggression, Violent Victimization, and the Overlap of Physical Aggression and Violent Victimization.

\section{Risk Factors}

Alcohol use. Alcohol use was measured with one item: "During the last 12 months, on how many occasions, or times, have you had alcoholic beverages to drink?" Response options included "0 occasions", "1-2 occasions", "3-5 occasions", "6-9 occasions", "10-19 occasions", "20-39 occasions" and "40 or more occasions". This measure was dichotomized into " 0 " indicating "no alcohol use", and " 1 " indicating alcohol use in the past 12 months.

Peer alcohol use. Peer alcohol use was measured with one item: "How many of your friends drink alcohol?". Responses ranged from 0 to 4, including "None", "Few", "Some", "Many", and "Almost all".

Lack of adult supervision. Unsupervised time was assessed with one item: "About how many hours a day, do you usually spend without an adult around?" Responses included: "None", "< 1 hour", "1-2 hours", "3-4 hours", and "5 or more hours".

Sadness/depression. Sadness/depression was measured with one item: "During the last month, how often have you felt sad or depressed?" Response values ranged from 1 to 3 , and included "Never", "1-3 times", and "4 or more times".

\section{Demographics}

Demographic variables included gender, age, natural parent household, race/ethnicity, U.S. born, and socioeconomic status.

Gender. Biological sex was measured $1=$ male and $0=$ female.

Age. Age was measured continuously in number of years.

Natural parent household. Family structure was assessed with one item: "Who do you live with most of the time?" Responses were coded as "Mother and Father together" vs "Other".

Race/ethnicity. Race/ethnicity was characterized as African American $(=1)$ or Hispanic $(=0)$ based upon student self-report data at baseline.

U.S. born. Nationality was assessed with one item: "How long have you lived in the United States?" Responses were coded "All of your life=1" versus "Foreign-born=0".
Low socioeconomic status. Socioeconomic status was measured with one item: "Do you receive free or reducedprice lunches at school?" Responses were coded as "Yes=1" versus "No or don't know=0".

\section{ANALYTIC STRATEGY}

Considering that the focus of our current study is examining the association between physical aggression perpetration and experiencing violent victimization, we employ a bivariate probit model versus more standard regression models. Standard regression analyses that estimate the effects of risk factors and demographic variables on outcomes such as physical aggression and violent victimization evaluate these relationships separately. That is, they ignore or are unable to account for the possible correlation in the error terms between the two outcomes. Comparatively, a bivariate probit model can be applied to model separate outcomes simultaneously [26]. By estimating rho $(\rho)$ (what we refer to as the overlap coefficient), we can consider the common error term between physical aggression and violent victimization [26, 27].

The first bivariate probit model provides the results from the naive model estimating the overlap coefficient $(\rho)$, and the next series of models enter in risk factors and demographic variables separately and then jointly to assess whether the association between physical aggression and violent victimization can be explained away by a shared commonality in risk factors and demographics. All multivariate models are estimated in Stata 11.0 using robust standard errors due to the nested nature of the data (e.g., individuals within schools) and adjusted for treatment condition.

\section{RESULTS}

The results from the naive bivariate probit model estimating the overlap coefficient $(\rho)$ demonstrates that there is a positive and significant $(p<.001)$ association between the error terms for physical aggression and violent victimization (see Table 2).

Table 2. Bivariate Probit Estimate of Overlap between Physical Aggression and Violent Victimization

\begin{tabular}{|ll|}
\hline & Overlap Coefficient (SE) \\
\hline \hline Rho $(\rho)$ & $.51(.03)$ \\
Likelihood-Ratio Test of Rho $(\rho)$ & $186.09 * * *$ \\
-2 Log Likelihood & $-1,851.04$ \\
$\mathrm{~N}$ & 1,440 \\
${ }^{*} \mathrm{p}<.05^{* *} \mathrm{p}<.01^{* * *} \mathrm{p}<.001$. & \\
\hline
\end{tabular}

Table 3 presents the bivariate probit models examining whether accounting for risk factors and demographic variables can explain away the correlation between the errors terms between perpetrating physical aggression and experiencing violent victimization. Regarding the first model, the results suggest that alcohol use is a significant risk factor for reporting physical aggression $(b=0.16, \mathrm{SE}=$ $0.08, p<$. 05) and reporting sadness/depression is a significant risk factor for being physically aggressive $(b=$ 
$0.09, \mathrm{SE}=0.04, p<.01)$ and for being violent victimized $(b=$ $0.16, \mathrm{SE}=0.04, p<.001)$. The direction of the effects for peer alcohol use and lack of adult supervision are both positive suggesting that having a greater proportion of peers who use alcohol and spending larger amounts of time in the absence of adult supervision increase the risk for being physically aggressive and violent victimized (although these effects are not significant). Nevertheless, these risk factors are unable to completely account for the correlation in the error terms between the two outcomes considering that the overlap coefficient $(\rho)$ still remains significant.

The next model assesses the effects of the demographic variables on the correlation in the error terms between physical aggression perpetration and violent victimization. The only demographic variable with a common effect on both outcomes is age. Specifically, younger individuals had significantly less risk for reporting physical aggression $(b=-$ $0.17, \mathrm{SE}=0.07, p<.01)$ and violent victimization $(b=-0.11$, $\mathrm{SE}=0.06, p<.10)$. In addition, youth who resided in natural two parent households had significantly less risk for experiencing violent victimization $(b=-0.24, \mathrm{SE}=0.08, p<$. 001), whereas youth who were born in the U.S. had a marginally higher risk for experiencing violent victimization $(b=0.18, \mathrm{SE}=0.11, p<.10)$. However, similar to the risk factor model described above, the demographic variables were unable to explain away the correlation in the error terms as the overlap coefficient $(\rho)$ was still significant.

The next to last bivariate probit model provides the results of the fully specified model incorporating the risk factors and the demographic variables simultaneously, and the final model in Table $\mathbf{3}$ presents these results adjusted for prior baseline physical aggression as measured at the end of $8^{\text {th }}$ grade. The results indicate that alcohol use $(b=0.18, \mathrm{SE}=$ $0.08, p<.05)$ and sadness/depression $(b=0.14, \mathrm{SE}=0.04, p<$. $01)$ along with being younger $(b=-0.21, \mathrm{SE}=0.08, p<.01)$, African American $(b=0.15, \mathrm{SE}=0.08, p<.10)$, and male $(b=$ $0.19, \mathrm{SE}=0.07, p<.01)$ were significantly associated with perpetrating physical aggression. Comparatively, alcohol use $(b=0.13, \mathrm{SE}=0.08, p<.10)$, sadness/depression $(b=0.18$, $\mathrm{SE}=0.04, p<.001)$, age $(b=-0.13, \mathrm{SE}=0.07, p<.10)$, natural two parent household $(b=-0.19, \mathrm{SE}=0.08, p<.05)$, and U.S. born $(b=0.18, \mathrm{SE}=0.11, p<.10)$ were significantly associated with experiencing violent victimization. Substantively similar results were found in the model adjusted for prior baseline physical aggression as measured at the end of $8^{\text {th }}$ grade. In the end, none of the bivariate probit models including the model adjusted for baseline physical aggression could account for the significant correlation between the error terms for perpetrating physical aggression and experiencing violent victimization.

\section{DISCUSSION}

Prior research has suggested that offenders and victims are often one and the same [4, 6, 9, 28, 29], and this finding is not unique to the United States (e.g., [21, 30-32]. Furthermore, more recent studies have elaborated on the shared commonality of risk factors for offending and victimization with a particular focus on routine activities/lifestyles and social context [3, 19]. Taken

Table 3. Bivariate Probit Models Predicting the Joint Occurrence of Physical Aggression and Violent Victimization along with Risk Factors, Demographics, and Prior Physical Aggression

\begin{tabular}{|c|c|c|c|c|c|c|c|c|}
\hline & $\begin{array}{c}\text { Perpetrator } \\
\text { b (SE) }\end{array}$ & $\begin{array}{l}\text { Victim } \\
\text { b (SE) }\end{array}$ & $\begin{array}{c}\text { Perpetrator } \\
\text { b (SE) }\end{array}$ & $\begin{array}{l}\text { Victim } \\
\text { b (SE) }\end{array}$ & $\begin{array}{c}\text { Perpetrator } \\
\text { b (SE) }\end{array}$ & $\begin{array}{l}\text { Victim } \\
\text { b (SE) }\end{array}$ & $\begin{array}{l}\text { Perpetrator } \\
\text { b (SE) }\end{array}$ & $\begin{array}{l}\text { Victim } \\
\text { b (SE) }\end{array}$ \\
\hline \multicolumn{9}{|l|}{ Risk Factors } \\
\hline Alcohol Use & $.16(.08)^{*}$ & $.09(.08)$ & & & $.18(.08)^{*}$ & $.13(.08)^{+}$ & $.15(.08)^{+}$ & $.12(.08)$ \\
\hline Peer Alcohol Use & $.04(.03)$ & $.05(.03)$ & & & $.03(.03)$ & $.03(.03)$ & $-.03(.03)$ & $.01(.04)$ \\
\hline Lack of Adult Supervision & $.01(.03)$ & $.03(.03)$ & & & $-.01(.02)$ & $.02(.03)$ & $-.02(.02)$ & $.01(.03)$ \\
\hline Sadness/Depression & $.09(.04)^{* *}$ & $.16(.04)^{* * *}$ & & & $.14(.04)^{* *}$ & $.18(.04)^{* * *}$ & $.08(.04)^{+}$ & $.15(.04)^{* * *}$ \\
\hline \multicolumn{9}{|l|}{ Demographics } \\
\hline Male & & & $.08(.07)$ & $-.05(.06)$ & $.19(.07)^{* *}$ & $.08(.07)$ & $.14(.08)^{+}$ & $.05(.07)$ \\
\hline Age & & & $-.17(.07)^{* *}$ & $-.11(.06)^{+}$ & $-.21(.08)^{* *}$ & $-.13(.07)^{+}$ & $-.24(.07)^{* *}$ & $-.14(.07)^{*}$ \\
\hline Natural Parent Household & & & $-.06(.08)$ & $-.24(.08) * * *$ & $-.01(.08)$ & $-.19(.08)^{*}$ & $-.03(.08)$ & $-.20(.08)^{* *}$ \\
\hline African American & & & $.10(.08)$ & $.01(.07)$ & $.15(.08)^{+}$ & $.01(.07)$ & $.03(.09)$ & $-.05(.08)$ \\
\hline U.S. Born & & & $.12(.12)$ & $.18(.11)^{+}$ & $.10(.12)$ & $.18(.11)^{+}$ & $.09(.13)$ & $.18(.11)^{+}$ \\
\hline Low Socioeconomic Status & & & $-.01(.08)$ & & $-.03(.08)$ & $-.10(.09)$ & $-.07(.08)$ & $-.12(.09)$ \\
\hline Prior Physical Aggression & & & & & & & $.14(.02)^{* * *}$ & $.06(.02)^{* *}$ \\
\hline Rho $(\rho)$ & $.50(.03)$ & & $.51(.03)$ & & $.50(.03)$ & & $.50(.03)$ & \\
\hline Likelihood-Ratio Test of Rho ( $\rho$ ) & $184.80^{* * *}$ & & $187.74 * * *$ & & $183.68^{* * *}$ & & $187.07 * * *$ & \\
\hline-2 Log Likelihood & $-1,800.40$ & & $-1,787.14$ & & $-1,739.67$ & & $-1,714.13$ & \\
\hline $\mathrm{N}$ & 1,415 & & 1,403 & & 1,381 & & 1,377 & \\
\hline
\end{tabular}


together, this literature begs the question that perhaps the link between victimization and offending is spurious [33] in the sense that the correlation between the two outcomes can be explained by the overlap in covariates that predict both events. The current study attempted to directly examine this particular issue using a large sample of urban minority Chicago youth and young adults. Several important findings emerged and are discussed in greater detail below.

The initial results from the naïve bivariate probit model revealed a significant and strong association between reporting perpetrating physical aggression and experiencing violent victimization. This finding, in and of itself, is consistent with prior research investigating the victimoffender overlap in general [22] and among youth specifically [3, 6, 19]. Furthermore, the more complex bivariate probit models identified several risk factors that were shared across both outcomes such as alcohol use and sadness/depression as well as reporting common demographic variables that were predictive of perpetrating physical aggression and reporting violent victimization (e.g., age). However, the results also demonstrated other demographic factors that appeared salient for offending but not victimization such as biological sex whereas residing in a natural two parent household significantly reduced the risk of victimization but not offending. Finally, the fully specified bivariate probit models unadjusted and adjusted for baseline physical aggression indicated that the shared commonality among the risk factors and demographic variables examined here were not able to explain away the significant correlation between the error terms for perpetrating physical aggression and experiencing violent victimization.

Prior to discussing the theoretical and policy implications it is important to note a few study limitations. First, the sample used in this study included only African American and Hispanic youth and young adults. Therefore, the degree to which these findings generalize to other non-African American and non-Hispanic youth and young adult populations remains an area for further research. Having said this, considering the fact that a significant and positive association between victimization and offending has been reported elsewhere in a number of cross-cultural and international studies including Colombia, Great Britain, Iceland, and the Netherlands (e.g., [21, 30-32], the generalizability of our results seems plausible. Second, although these data span across two developmental periods (mid-adolescence to young adulthood-ages 14-age 18), information is not available for earlier developmental periods (early childhood) and/or middle or late adulthood. Future research is encouraged to investigate the association between victimization and offending across earlier dimensions of the life-course and extend the follow-up into middle and late adulthood when possible. Third, the risk factors that were included in this study were based on specific theoretical frameworks, most notably routine activities/lifestyles. It is quite possible that other theoretical explanations with unique risk factors that were not incorporated into our multivariate models may be able to account for the shared overlap in the error terms for physical aggression and violent victimization. Future research should make an effort to include other theoretical explanations and risk factors such as parental supervision and attachment [34], neighborhood disadvantage [35], and self-control [36].

With regard to theoretical implications, our results suggest that criminological theories that are predominantly offender-focused or victim-focused risk being mis-specified. For example, biological sex is one of the strongest known correlates of offending, and victim-offender overlap research has demonstrated that sex differences in offending can account for a large portion of the variability in victimization $[37,38]$. However, there still remains a great deal of unexplained variability. This result in conjunction with our findings suggest that biological sex and other risk factors such as alcohol use, peer alcohol use, lack of adult supervision, and sadness/depression cannot render the association between offending and victimization insignificant. Therefore, any criminological theories and empirical tests of these theories that ignores victimization when predicting offending or ignores offending when predicting victimization will be mis-specified.

Turning toward policy, the results from this study suggest that there is a considerable degree of commonality in the risk factors for being a perpetrator of physical aggression and being a victim of violence. Furthermore, these risk factors alone cannot negate the strength of the shared overlap among victims and offenders. Thus, in a time of limited prevention and treatment resources, policy makers should be investing in evidence-based programs that have demonstrated success in violence prevention/intervention. Ultimately, regardless of the focus, successful programs that aim to reduce aggression or prevent victimization are likely to simultaneously benefit the other component considering the victim-offender overlap.

\section{ACKNOWLEDGMENTS}

This study was funded by grants from the National Institute on Alcohol Abuse and Alcoholism and the National Institute on Minority Health and Health Disparities (AA013458 and AA016549). The authors thank Karen Alfano, MBA and Carolyn Kulb, B.A., for survey design and management of data collection, Kian Farbakhsh, M.S., for database design and management, and Cheryl Perry, PhD, for her overall contributions to the PNC study. We gratefully acknowledge the participation of students and parents.

\section{CONFLICT OF INTEREST}

None declared.

\section{REFERENCES}

[1] Substance Abuse and Mental Health Services Administration. The NSDUH Report: State Estimates of Drunk and Drugged Driving. Rockville, MD: Center for Behavioral Health Statistics and Quality 2010.

[2] Maldonado-Molina MM, Reingle JM, Jennings WG, Prado W. Drinking and driving among immigrant and US-born Hispanic young adults: results from a longitudinal and nationally representative study. Addict Behav 2011;36: 381-8.

[3] Schreck CJ, Stewart EA, Osgood DW. A reappraisal of the overlap of violent offenders and victims. Criminology 2008; 46: 871-906.

[4] Jensen GF, Brownfield D. Gender, lifestyles, and victimization: Beyond routine activity theory. Violence Victims 1986; 1: 85-99.

[5] Schreck CJ, Fisher BS, Miller JM. The social context of violent victimization: a study of the delinquent peer effect. Justice Q 2004; 21: 23-48. 
[6] Rutman S, Park A, Castor M, Taualii M, Forquera R. Urban American Indian and Alaska Native youth: Youth risk behavior survey 1997-2003. J Maternal Child Health 2008; 12: S76-S81.

[7] Schreck CJ, Wright RA, Miller JM. A study of individual and situational antecedents of violent victimization. Justice Q 2002; 19: 159-80.

[8] Osgood DW, Wilson JK, O'Malley PM, Bachman JG, Johnston LD. Routine activities and individual deviant behavior. Am Sociol Rev 1996; 61: 635-55.

[9] Office of Applied Studies. The NSDH report: Substance use and substance use disorders among American Indians and Alaska Natives. Rockville: MD: Substance Abuse and Mental Health Services Administration 2007.

[10] Felson RB. Kick 'em when they're down: Explanations of the relationship between stress and interpersonal aggression and violence. Sociol Q 1992; 33: 1-16.

[11] Baskin DR, Sommers IB. Casualties of community disorder: Women's careers in violent crime. Boulder, CO: Westview 1997.

[12] Anderson E. Code of the street: Decency, violence, and the moral life of the inner city. New York, NY: W. W. Norton; 1999.

[13] Jacobs BA, Wright R. Street justice: Retaliation in the criminal underworld. New York, NY: Cambridge 2006.

[14] Beauvais F. American Indians and alcohol. Alcohol Res Res World 1998; 22: 253-71.

[15] Broidy LM, Daday JK, Crandall CS, Klar DP, Jost PF. Exploring demographic, structural, and behavioral overlap among homicide offenders and victims. Homicide Stud 2006; 10: 155-80.

[16] Chen $X$. The link between juvenile offending and victimization: The influence of risky lifestyles, social bonding, and individual characteristics. Youth Violence Juvenile Justice 2009; 7: 119-35.

[17] Kunitz S, Zhao H, Wheeler DR, Woodall WG. Predictors of conviction and sentencing of DWI offenders in New Mexico county. Traffic Inj Prev 2006; 7: 6-14.

[18] Kunitz SJ, Woodall WG, Zhao H, Wheeler DR, Lillis R, Rogers E. Rearrest rates after incarceration for DWI: A comparative study in a southwestern US county. Am J Public Health 2002; 92: 1826-31.

[19] May PA, Goassage JP. New data on the epidemiology of adult drinking and substance use among American Indians of the northern states: Male and female data on prevalence, patterns, and consequences. Am Ind Alasa Native Mental Health Res 2001; 10: $1-26$.

[20] Loeber R, Pardini D, Homish DL, et al. The prediction of violence and homicide in young men. J Consult Clin Psychol 2005; 73: 1074-88.

[21] Klevens J, Duque LF, Ramirez C. The victim-offender overlap and routine activities: Results from a cross-sectional study in Bogota, Columbia. J Interpers Violence 2002; 17: 206-16.

[22] Silver E, Piquero AR, Jennings WG, Piquero N, Lieber M. Assessing the violent offending and violent victimization overlap among discharged psychiatric patients. Law Hum Behav (in press).
[23] Komro KA, Perry CL, Veblen-Mortenson S, et al. Brief report: the adaptation of Project Northland for urban youth. J Ped Psychol 2004; 29(6): 457-66.

[24] Komro KA, Perry CL, Veblen-Mortenson S, et al. Outcomes from a randomized controlled trial of a multi-component alcohol use preventive intervention for urban youth: Project Northland Chicago. Addiction 2008; 103: 606-18.

[25] Tobler AL, Komro KA. Contemporary options for longitudinal follow-up: Lessons learned from a cohort of urban adolescents. Eval Program Plann 2011; 34: 87-96.

[26] Galvan F, Caetano R. Alcohol use and related problems among ethnic minorities in the United States. Alcohol Res Health 2003; 27: 87-94.

[27] Akers RL. Deviant Behavior: A social learning approach. 1st ed. Belmont, CA: Wadsworth 1973.

[28] Lauritsen JL, Laub JH. Understanding the link between victimization and offending: New reflections on an old idea. Crime Prev Stud 2007; 22: 55-75.

[29] Maldonado-Molina MM, Reingle JR, Jennings WJ. Does alcohol use predict violent behaviors? the relationship between alcohol use and violence in a nationally representative longitudinal sample. Youth Violence Juvenile Justice 2011; 9: 99-111.

[30] Sampson RJ, Lauritsen JL. Deviant lifestyles, proximity to crime, and the offender-victim link in personal violence. J Res Crime Delinquency 1990; 27: 110-39.

[31] U.S. Department of Health and Human Services. Results from the 2009 National Survey on Drug Use and Health: Summary of findings. Rockville, MD: Substance Abuse and Mental Health Services Administration, Office of Applied Studies 2010.

[32] Office of Applied Studies. The NSDUH report: Use of marijuana and blunts among adolescents: 2005. Rockville: MD: Substance Abuse and Mental Health Services Administration 2007.

[33] Chartier K, Caetano R. Ethnicity and health disparities in alcohol research. Alcohol Res Health 2010; 33: 152-60.

[34] Leiber MJ, Mack KY, Featherstone RA. Family structure, family processes, economic factors, and delinquency. Youth Violence Juvenile Justice 2009; 7: 79-99.

[35] Wikstrom PH, Loeber R. Do disadvantaged neighborhoods cause well-adjusted children to become adolescent delinquents? A study of male juvenile serious offending, individual risk and protective factors, and neighborhood context. Criminology 2000; 38: 1109-42.

[36] Gibson CL, Sullivan CJ, Jones S, Piquero AR. "Does it take a village?": Assessing neighborhood influences on children's self control. J Res Crime Delinquency 2010; 47: 31-62.

[37] Schreck CJ. Criminal victimization and low self-control: an extension and test of a general theory of crime. Justice Q 1999; 16: 633-54.

[38] Wood D. A review of research on alcohol and drug use, criminal behavior, and the criminal justice response in American Indian and Alaska Native communities: U.S. Department of Justice 2010.

(C) Jennings and Komro; Licensee Bentham Open.

This is an open access article licensed under the terms of the Creative Commons Attribution Non-Commercial License (http: //creativecommons.org/licenses/by$\mathrm{nc} / 3.0 /$ ) which permits unrestricted, non-commercial use, distribution and reproduction in any medium, provided the work is properly cited. 